\title{
Research of Reference and Translation
}

\author{
Xia Zhou ${ }^{a}$, Jiajing Wang ${ }^{b}$ \\ North China Electric Power University, Baoding 071000, China. \\ a1192880729@qq.com, b1192880729@qq.com
}

Keywords: Reference; E-C translation; translation means and techniques.

\begin{abstract}
In their book Cohesion in English, Halliday and Hasan first applied the term of text cohesion after which cohesion and coherence have been attracting great attention in the linguistic and translation circle. Cohesion is seen as a necessary element in text production and holds an important position in text translation. Translators' knowledge and mastery of the similarities and differences in cohesive devices of two languages are crucial. Because they not only affect the understanding of source text but also influence the quality of the target text. Cohesion is studied in both a narrow sense and a broad one. The latter is consisted of semantic and structural cohesion. Semantic cohesion refers to five types of cohesion devices proposed by Halliday and Hasan, that is, reference, substitution, ellipsis, conjunction and lexical cohesion. And the structural cohesion refers to parallelism, theme-rhyme structure and information structure. The former is semantic cohesion which includes grammatical devices and lexical devices which cohere the sentences into a text. This paper chooses reference as the research objects. The similarities and differences between English and Chinese reference are compared and contrasted. To handle the differences, this paper studies the techniques and means in E-C translation.
\end{abstract}

\section{Introduction}

In the recent years, the text linguistic has made great progress, which held the opinion that the text as a unified whole should be regarded as the fundamental unit of communication. So the text should be the basic unit of translation as well. To achieve the dynamic communication of different languages, translators must comprehend the source text correctly and retextualize it as a target text with all features natural to the receptors.

So "text" must be explained. Halliday and Hasan's [1] definition: "the word TEXT is used in linguistics to refer to any passage, spoken or written, of whatever length, that does form a unified whole". To express the features of a text, there is a concept of "textuality" which meets seven standards: intentionality, acceptability, informativity, situationality, intertextuality, cohesion, and coherence. Failure to comply with any of these seven characteristics makes a text non-textual.

Cohesion as one of the linguistic features of texts, together with coherence in texts, is the core of the studies of text linguistics. Naturally, the studies on it can definitely make valuable contributions to translation at the textual level. This paper aims to study one of the textual cohesive devices between English and Chinese, analyze the differences herein and discover their influence on translation in E-C in order to help translators to comprehend the source text correctly and construct natural translation that is following the cohesion convention of the target text.

\section{Reference}

Reference is a device that allows the receiver to trace participants, entities, events, etc. in a text. The reference is divided into exophora and endophora. The interpretation of the former depends on the context of situation. In contrast, the latter refers to a reference within the text. Halliday and Hasan point out that only endophoric reference which may be anaphoric or cataphoric plays a part in textual cohesion. That is to say, reference is limited to relationship of identity which is kept by two linguistic expressions, instead of a direct relationship between words and extra-linguistic objects. 
Halliday and Hasan further divide reference into three subsets: personal, demonstrative and comparative.

In terms of the classification of reference, Chinese and English bear no evident difference. Chinese also possesses the three types of reference: personal, demonstrative and comparative reference and can be anaphoric and cataphoric too. However, because English is hypotactic and Chinese is paratactic, they differ a lot in the usage and the using frequency of reference. The creation of coherent text in English depends upon overt cohesive devices, while Chinese textual cohesion and coherence rely more on such covert devices as semantic and logical relations instead of overt cohesive devices.

As far as reference is concerned, the English text requires clearly stated referential relations, while the translator should try to avoid overt cohesive devices as many as possible when rendering the English text into Chinese. Otherwise, the translation process will inevitably bring forwards a non-comnicative target text.

\subsection{Personal Reference}

Personal reference is realized through pronoun (e.g. I, you, he, she, they, him, her, them, etc.), possessive determiner (e.g. your, his, her, them, etc.) and possessive pronoun (e.g. mine, his, hers, theirs, etc.) in English.

Both English and Chinese employ similar personals for both antaphoric and cataphoric cohesion. Real translation problem lies in their differences in usage and using frequency. Generally speaking, personals are not so frequently used in Chinese as in English, which requires the translator to omit the English personals wherever it is possible and necessary. In fact, Chinese text prefers zero anaphora and lexical repetition.

Example 1: For two weeks, he had been studying the house, looking at its rooms, its electrical wiring, its path and its garden.

两周以来，他一直注意观察房子的情况，查看各个房间，留心电线的走向、通道和花园的 布局。[2]

In this example, the ST uses for "its" to refer to "the house", while Chinese version uses zero anaphora. However, Chinese readers have no difficulty to recognize the textual cohesion and are also able to obtain concise and more acceptable Chinese version.

\subsection{Demonstrative Reference}

There are three kinds of words used in English demonstrative reference, that is, selective nominal demonstrative: this, that, these, those; definite article: the; demonstrative adverbs: here, there, now, then.

Chinese has “这” and “那” corresponding to English “this” and “that”. However, according to some relevant statistics, "in English the ratio of the absolute frequency of usage of 'this' to that of 'that' is about 1:2, while in Chinese the ratio is about 2:1" [3]. That is, English texts usually prefer "that" in referring anaphorically while Chinese texts prefer “这”.

Example 2: “Oh, Edgar, darling! Heathcliff's come back--he is!” and she tightened her embrace to a squeeze.

"Well, well,” cried her husband, crossly, “don’t strangle me for that!...” (Emily Brontë: Wuthering Heights)

“啊，埃德加，亲爱的！希刺克厉夫回来了一一他是回来啦！”她拼命地搂住他。

“好啦, 好啦。”她丈夫烦恼地叫道, “不要为了这个就要把我勒死啦！......” [4]

“That” in the ST refers to a fact "Heathcliff's come back" related in the former text, and it is translated into “这个” in Chinese.

In addition, the choice of near and remote demonstratives and adverbs in Chinese is determined more by psychological factors than by real-world time and space, as is the case in English [5].

Example 3: She could still remember the monkey she had seen several years before at a temple fair at home--it kept grinning and showing a mouthful of gleaning white teeth. That was her last happy memory...

她到现在还记得很明白的是五六年前的土地庙的香市时钟看见一只常常会笑的猴子，一口 


\section{的牙齿那么白！但这也是她最后一次快乐的记忆，…...}

"That" refers to a scene happened several years ago, which expresses the sense of remoteness in time. However, the Chinese writer uses “这” indicating that he doesn't feel psychological remoteness for such scene. So this actually distant scene is converted into “这” according to the feature of Chinese demonstrative reference.

Noticeably, in Chinese, there is no exact equivalent to English definite article "the". The translators prefer to use “这” and “那” instead of definiteness in such cases.

Example 4: One moonlit evening I dreamed of a certain fish. The fish was graygreen against lightcolored stones at the bottom of a deep pool, breathing a slow, unperturbed breathing, the largest fish I had ever imagined living in the river. (Barry Lopez: “Drought”)

一个月夜, 我梦到一种鱼。由于池水很深, 池底的石头颜色很浅, 这种鱼呈灰绿色, 它悠 然自得, 缓缓地呼吸, 这是在我的想象中最大的一种鱼。[6]

“The fish” is used to identify “a certain fish” I dreamed of. In Chinese, “这种” is used to indicate “我梦到的一种”, which both achieves cohesiveness in TT and corresponds to the original definiteness.

\subsection{Comparative Reference}

Comparative reference is indicated through the comparative degrees of adjectives and adverbs and some words with comparative meaning (such as same, so, as, equal, such, similar(ly), different(ly), other, otherwise, likewise, etc.), the use of the former makes particular comparison, the latter makes general comparison. General comparison involves likeness or unlikeness without considering any particular property. That is, two things may be the same, similar or different. Particular comparison expresses things in respect of a particular property, which is involved in the comparison of quantity and quality.

In general comparison, English and Chinese are similar, such as "same”-_“相同的”, “indentical”-_“一样的”, “likewise”--“同样的”, “else”-_“其他的”, etc..

Particular comparison is realized through lexical and structural means as well as comparative degree of adjectives and adverbs. However, Chinese adjectives and adverbs do not have such inflective form "-er", but the comparison can still be achieved by some structures combined with lexical means, such as “比……更/更加(还; 还要)”, “比……得多”, “不如……那样……”. “再没 有比……更……”, etc. [7].

Example 5: The expression of her face seemed disturbed and anxious...

She seated herself by me again: her countenance grew sadder and graver and her clasped hands trembled. (Emily Brontë: Wuthering Heights)

她脸上的表情看来又烦又忧虑不安。……

她又在我旁边坐下来，她的神气变得更忧伤、更严肃，她紧攥着的手在颤抖。[4]

This example shows the translation of a particular comparison achieved by comparative degree of adjectives and the Chinese version employs “更忧伤、更严肃”. The TT has no corresponding forms to comparative degree, but its lexical means “更” achieved the same meaning.

Generally speaking, English and Chinese do not have significant differences in comparative reference, so it is convenient to achieve E-C translation.

\section{Conclusion}

Through the study of reference and translation, there constructs such awareness: to achieve dynamic communication between English and Chinese, we must not mechanically apply the original cohesive devices to target text. Otherwise, the translationese becomes inevitable. So the differences between English and Chinese cohesive devices should be attached great attention.

English uses more reference items than Chinese does. Under most circumstances, the translator should either omit them or repeat the nouns in the Chinese translation. And the specific techniques on E-C translation have also been described in detail and supported by lots of examples in this paper. All of the work aims to provide better understanding of ST and natural expression of TT for 
translators.

\section{References}

[1] Halliday, M.A.K. \& Hasan, R. Cohesion in English [M]. London: Longman, 1976.

[2] Lian Shu. Comparative study of English and Chinese [M]. higher education publishing house, 1993

[3] Ke Ping (Ke Ping). Linguistics [M]. Contrastive Nanjing: Nanjing Normal University Press, 1999

[4] Yang Yi's translation. Wuthering Heights [M]. Yilin press, 2011

[5] Xu Yu Long. An introduction to comparative linguistics [M]. Shanghai: Shanghai foreign language education press, 1992

[6] Chen Hongwei translation. "By" Barry Lopez [J]. Drought Chinese translation, 2001, (1): 67-71. A comparative study of cohesive devices in English and Chinese texts of

[7] Zhu Yongsheng al. [Z]. et Shanghai: Shanghai foreign language education press, 2001 